\title{
Robotic biomimicry demonstrates behavioral control of planktonic dispersal in the sea
}

\author{
S. G. Morgan ${ }^{1,2, *}$, C. D. Dibble ${ }^{1}$, M. G. Susner ${ }^{1}$, T. G. Wolcott ${ }^{3}$, D. L. Wolcott $^{3}$, \\ J. L. Largier ${ }^{1,2}$ \\ ${ }^{1}$ Coastal and Marine Sciences Institute, Bodega Marine Laboratory, University of California Davis, 2099 Westshore Drive, \\ Bodega Bay, CA 94923-0247, USA \\ ${ }^{2}$ Department of Environmental Science and Policy, University of California Davis, 1 Shields Avenue, Davis, CA 93510, USA \\ ${ }^{3}$ Marine, Earth and Atmospheric Sciences, North Carolina State University, 2800 Faucette Drive, \\ 1125 Jordan Hall Campus Box 8208, Raleigh, NC 27695, USA
}

\begin{abstract}
Plankton are widely considered to be at the mercy of ocean currents, even after decades of research revealing that plankton regulate dispersal by positioning themselves in surface and bottom currents flowing in different directions. The degree of effectiveness of these behaviors remains controversial, because tiny plankters cannot be tracked at sea. Here, we experimentally tested the effectiveness of 3 vertical positioning behaviors in nature by developing a biomimetic robot that emulates them. We conducted a challenging test by deploying them in complex circulation during strong upwelling winds and wind relaxation and reversal events. Behavior alone dramatically affected transport. Transport trajectories of robots with 3 different behaviors diverged markedly while those sharing the same behavior were very similar. Moreover, all 3 behaviors produced trajectories that matched previously modeled projections during both upwelling and relaxation conditions at the study site: shallow plankton disperse far, deep plankton move little, and plankton migrating from depth during the day to the surface at night travel an intermediate distance. The ability of weakly swimming plankton to control their fate and replenish populations in a dynamic ocean is of central importance to the ecology and evolution of marine life and to the management of resources in a changing climate.
\end{abstract}

KEY WORDS: Dispersal $\cdot$ Plankton $\cdot$ Larval transport $\cdot$ Vertical migration $\cdot$ Robotics

\section{INTRODUCTION}

Dispersal is fundamental to the ecology and evolution of marine life, with implications for spawning migrations, species range extensions due to climate change, the spread of invasive species, management of commercial species as one or more stocks, and the design, siting, and evaluation of networks of marine protected areas (Strathmann et al. 2002, Morgan 2014, Burgess et al. 2016). However, dispersal is challenging to determine in the sea, where most marine animals produce vast numbers of microscopic larvae that develop for weeks in the plankton. The sheer numbers of larvae produced, their poor swim-

*Corresponding author: sgmorgan@ucdavis.edu ming capabilities, and episodic settlement events have led to the widespread belief that advection by strong currents and other sources of mortality often overwhelm larvae, carrying them far from natal populations, resulting in highly variable recruitment in time and space that is difficult to forecast (Hjort 1914, Thorson 1950, Scheltema 1975, Caley et al. 1996). The actual contribution of advection to mortality remains uncertain because the fate of tiny plankton cannot be tracked for weeks in ocean currents. Instead, estimates have been largely based on logical inference, small-scale empirical studies, and theoretical and numerical oceanographic models which often do not incorporate larval behavior, thereby

() The authors 2021. Open Access under Creative Commons by Attribution Licence. Use, distribution and reproduction are unrestricted. Authors and original publication must be credited. 
overestimating the contribution of advection to mortality in the plankton (Morgan 1995, 2001, White et al. 2014, Shanks \& Morgan 2018).

A long history of observations in the laboratory and field indicate that zooplankton may limit losses due to advection away from adult populations by moving vertically between currents that differ in speed or direction with depth (Young 1990, Queiroga \& Blanton 2005, Naylor 2006, Morgan 2014, 2020, Epifanio \& Cohen 2016). Zooplankton commonly change depth over the diel cycle (diel vertical migration; DVM), tidal cycle (tidal vertical migration; TVM) and during development (ontogenetic vertical migration; OVM). Early skeptics discounted the ability of zooplankton to effectively regulate depth in the field (e.g. DeWolf 1973, McCleave \& Wippelhauser 1987). They argued that zooplankton drifting in open water do not have fixed visual or tactile references to judge speed and direction of water flow, and they remain in the same parcel of water over a tidal cycle, lacking changes in cues to stimulate TVMs. Moreover, responses of zooplankton to isolated variables in static laboratory conditions and complexes of variables in the field do not always match (Cronin \& Forward 1986, Young 1986, James et al. 2019), and depth regulation may be more challenging for weakly swimming ciliated larvae, such as polychaetes and mollusks, than stronger swimming larvae, such as crabs and fishes (Young 1995).

Decades of surveys across estuaries and the continental shelf suggest that both larvae of benthic species (meroplankton) and permanent residents of the plankton (holoplankton) limit dispersal. Larvae of some species remain nearshore throughout development, while larvae of other species are initially transported offshore and later return onshore to adult habitats, consistent with a cross-shelf migration (Bousfield 1955, Peterson 1998, Queiroga \& Blanton 2005, Morgan 2014, 2020). The evidence for the effectiveness of depth regulation is inferential and reveals little about alongshore dispersal given that larvae in sequential plankton samples may have originated from different alongshore locales. The advent of natural elemental marker and genetic relatedness techniques clearly indicate that larvae stay much closer to home than was widely believed (Swearer et al. 2002, Cowen \& Sponaugle 2009, Jones et al. 2009, Burgess et al. 2014), but these studies typically lack mechanistic companion studies on larval behavior showing how this was accomplished. Despite growing evidence that larval behavior limits dispersal and facilitates recruitment by both vertical and onshore swimming (Kingsford et al. 2002, Quei- roga \& Blanton 2005, Arvedlund \& Kavanagh 2009, Leis et al. 2011, Epifanio \& Cohen 2016, Morgan 2020), models still often do not incorporate larval behavior, and larval advection from natal populations is still considered to be a key determinant in limiting recruitment to populations and communities (Roughgarden et al. 1988, Menge et al. 2003, Broitman et al. 2008, Woodson et al. 2012, Menge \& Menge 2013).

Because individual zooplankters cannot be tracked at sea, the ability of zooplankton to regulate transport by vertical positioning could not be experimentally addressed until the advent of robotics and biomimicry (Vincent et al. 2006). We developed a novel instrumented robot, the Autonomous Behaving Lagrangian Explorer (ABLE; Fig. 1), that mimics verti-

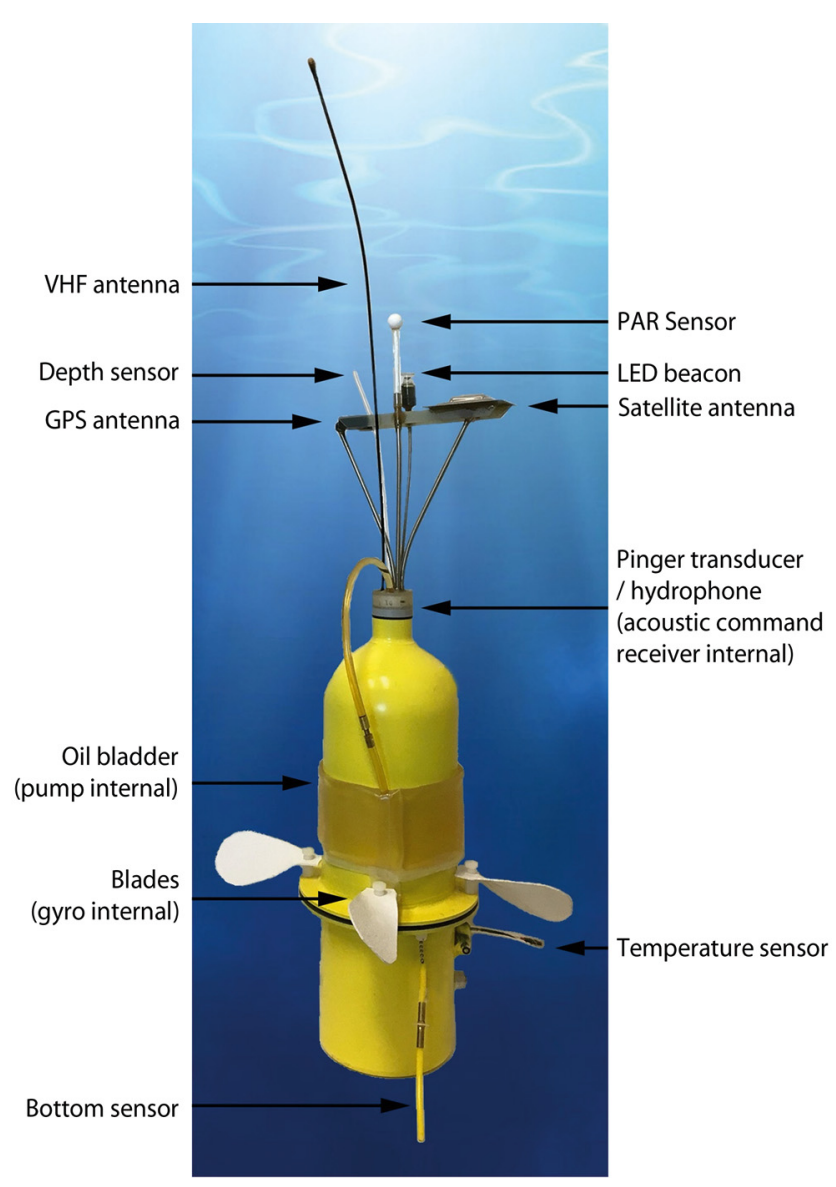

Fig. 1. The Autonomous Behaving Lagrangian Explorer (ABLE) weighs $3 \mathrm{~kg}$ and is $20 \mathrm{~cm}$ tall with a $15 \mathrm{~cm}$ antenna mast. It adjusts depth by pumping oil from an internal reserve into an external bladder to ascend, and the reverse to descend. A bottom sensor keeps it off the bottom. It logs vertical swimming speed by using a gyroscope to measure spinning induced by 'propeller' blades while profiling temperature and photosynthetically active radiation through the water column. We track it by GPS and home in on it by ultrasonic, VHF radio and LED beacons 
cal swimming and dispersal of meroplankton and holoplankton in real-world settings. We deployed our biomimetic robot in the upwelling system at Bodega Bay, northern California, USA, where we conducted 13 previous studies on the complex circulation and its effects on larval transport, including mapping the horizontal and vertical structure of water column properties and currents of Bodega Bay (Roughan et al. 2005), larval surveys for many species of invertebrates relative to water column structure and currents in the bay and nearshore coastal waters (Mace \& Morgan 2006a, Morgan \& Fisher 2010, Morgan et al. 2011, 2012, Nickols et al. 2013) as well as across the shelf (Morgan et al. 2009a,b, 2018, Hameed et al. 2018), modeling the effect of documented interspecific differences of larval behavior on transport in the bay (Roughan et al. 2005) and the shelf (Drake et al. 2013), and interspecific differences in physical processes delivering recruiting postlarvae onshore (Mace \& Morgan 2006b, Morgan et al. 2009a). If transport in the lee of Bodega Head is controlled by vertical swimming, we hypothesized that ABLEs simulating 3 common swimming behaviors of larvae would follow very different paths. In this region, strong, persistent alongshore winds from the north combine with the Coriolis effect to drive surface waters offshore and southward, while subsurface water flows onshore and upwells at the coast (Largier et al. 1993, Hickey 1998). In the bay, sheared flow occurs during northerly winds when nearsurface waters flow southward with the wind, while near-bottom waters flow upwind and upwell at the north shore in a way that concentrates depth-seeking larvae (Roughan et al. 2005, Mace \& Morgan 2006a, Morgan et al. 2011) (Fig. 2A). Winds peak during the afternoon and usually weaken at night (Dorman et al. 2006), reducing southward transport of near-surface water. When winds weaken or switch to a southerly direction, the surface flow reverses and flushes larvae from the bay (Morgan et al. 2012) (Fig. 2B).

During northerly wind, we hypothesized that ABLEs would be (1) retained in the bay if they remained
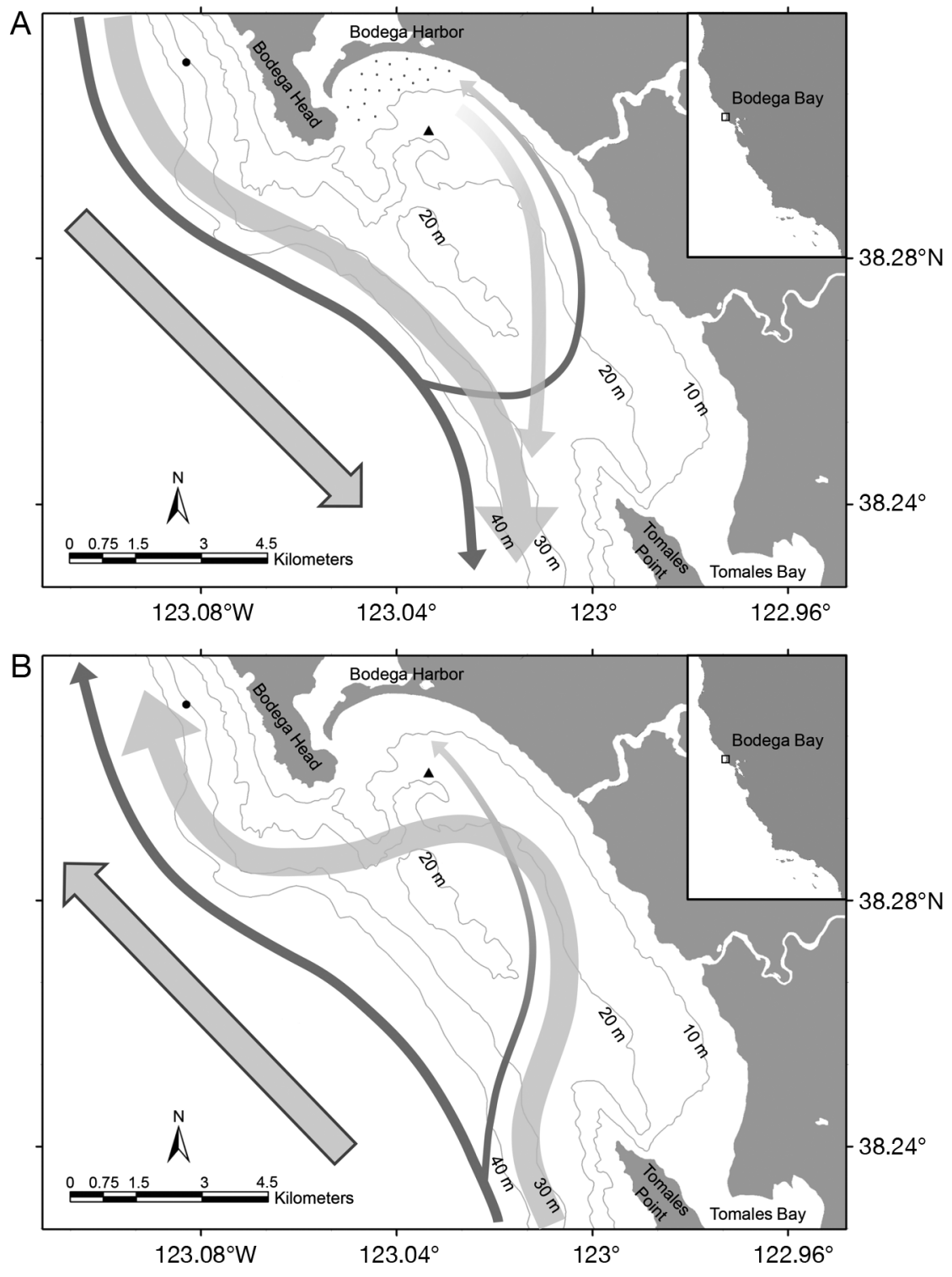

Fig. 2. Circulation in Bodega Bay, California, USA. (A) During strong northwesterly winds (large gray arrow), Bodega Head partially blocks the wind, slowing near-surface currents (light gray arrows) relative to the open coast while upwelling (stippling) occurs along the northern shore of the bay. Near-bottom (dark gray arrows) waters flow into the bay forming an eddy. (B) During weak northwesterly or southerly winds (large gray arrow), surface waters (light gray arrows) flow through the bay while near-bottom waters (dark gray arrows) flowing into the bay are partially obstructed from exiting by a shallow ridge crossing the northern mouth of the bay. The density of shading and width of arrows represent current speed. Solid circle: location of the mooring; solid triangle: location of deployments

near-bottom by maintaining a depth of $16 \mathrm{~m}$, (2) retained if they performed a 2-16 $\mathrm{m}$ DVM on days when winds subsided at night, (3) transported southward and seaward out of the bay if they performed DVM on days when winds persisted at night, and (4) transported southward and seaward farthest if they 
remained near-surface by maintaining $2 \mathrm{~m}$ depth. We also hypothesized that when winds weaken or become southerly, the flow reversal would transport ABLEs northward, with near-surface robots moving farthest, near-bottom ones moving least due to reduced flow from bottom drag, and those undertaking a DVM traveling an intermediate distance.

\section{MATERIALS AND METHODS}

We experimentally tested whether behavior controls transport by deploying ABLEs (Fig. 1) for about $24 \mathrm{~h}$. The ABLE is a neutrally buoyant body moving with the surrounding water without inertial forces, like drogues long used by oceanographers to determine circulation and velocities of surface currents, but capable of adaptively changing the depth of the water parcel it is tracking as a function of time and its measurements of the physical microenvironment, such as depth, temperature, light, and displacements by turbulence (Fig. 3). The ABLE has no structures like a float or pendant outside the parcel of water in which it is embedded and hence no extraneous drag to cause drift errors. However, ABLEs need to surface to obtain and report their position, which was done infrequently (every $4 \mathrm{~h}$ ) to minimize error due to time spent away from target depth (Fig. 3).

Three replicate ABLEs simulating 3 vertical behaviors for a total of 9 ABLEs were deployed 12 times in the lee of Bodega Head between the 10 and $20 \mathrm{~m}$ isobaths (deployments at $38.30075^{\circ} \mathrm{N}, 123.03342^{\circ} \mathrm{W}$ ) during a range of typical wind conditions (Table 1). We programmed ABLEs to remain $2 \mathrm{~m}$ below the surface, $16 \mathrm{~m}$ deep (otherwise $2 \mathrm{~m}$ above the bottom when in shallower water), or migrate from $16 \mathrm{~m}$ deep during the day to $2 \mathrm{~m}$ below the surface at night (DVM; Fig. 3). Based on a $14 \mathrm{~h}$ light and $10 \mathrm{~h}$ dark photoperiod, we programmed DVM ABLEs to start descending from the surface near dawn and ascend near dusk with transit taking approximately $12 \mathrm{~min}$. ABLEs recalculated their target depth every $10 \mathrm{~s}$ and
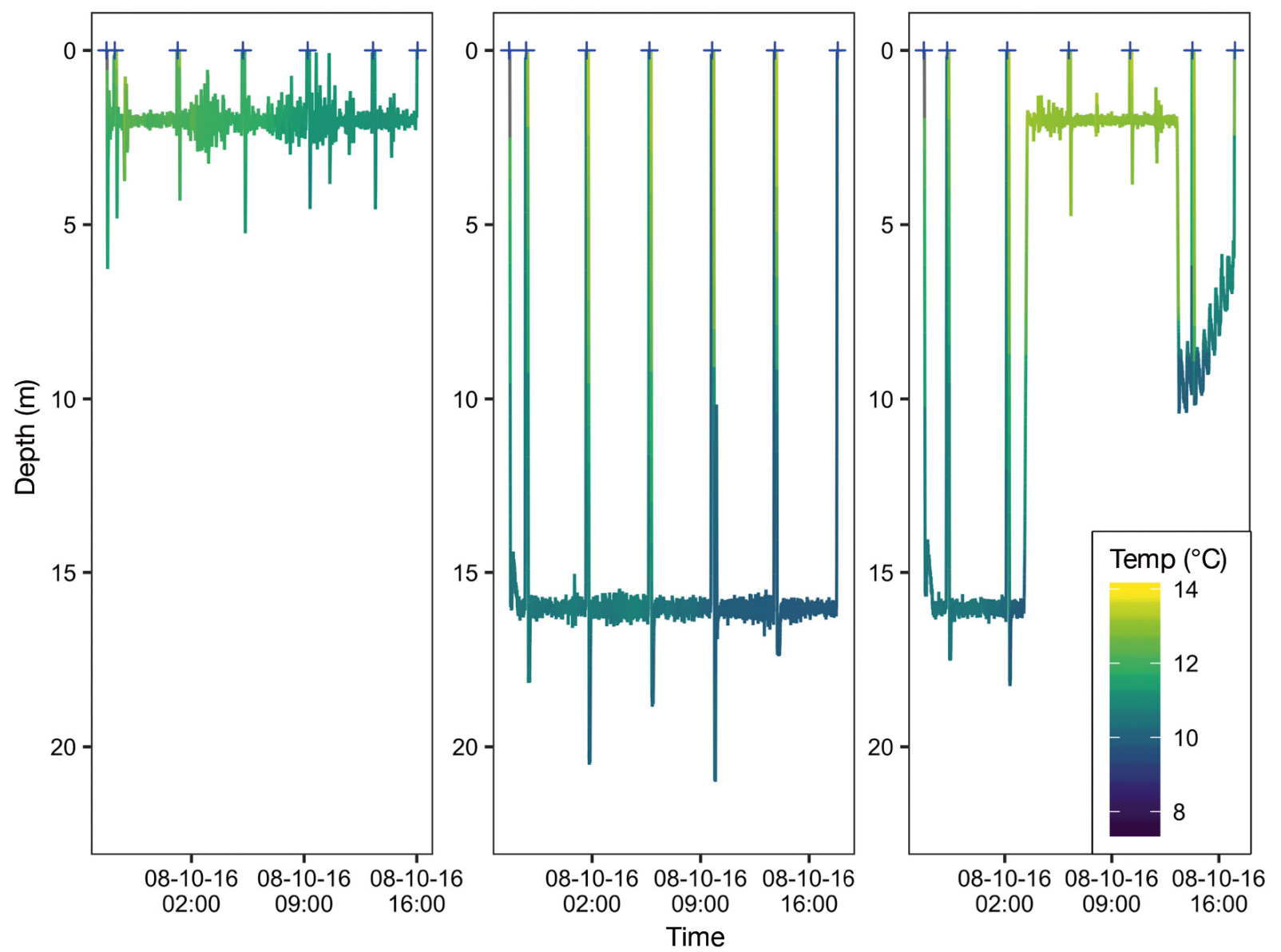

Fig. 3. Depth records from 10 August 2016 (time shown as GMT), of ABLEs targeting (A) a depth of $2 \mathrm{~m}$, (B) a depth of $16 \mathrm{~m}$, and (C) undertaking a diel vertical migration between $16 \mathrm{~m}$ during the day and $2 \mathrm{~m}$ at night. The rising trace in the right panel shows the ABLE sensing and remaining above a shoaling bottom. ABLEs made excursions to the surface for GPS fixes every $4 \mathrm{~h}$ 
Table 1. Mean $( \pm \mathrm{SE})$ wind conditions during 12 ABLE deployments. Representative trajectories of 6 of the deployments (indicated by asterisks) are illustrated in Fig. 4

\begin{tabular}{|c|c|c|}
\hline \multirow{2}{*}{ Date } & \multicolumn{2}{|c|}{ Wind stress $\left(\mathrm{N} \mathrm{m}^{-2}\right)$} \\
\hline & Alongshore & Cross-shore \\
\hline 19-21 August 2015 & $-0.008 \pm 0.001$ & $0.003 \pm 0.001$ \\
\hline 6-7 June 2016 & $0.001 \pm 0.001$ & $0.01 \pm 0.001$ \\
\hline 16-17 June 2016 & $0.012 \pm 0.002$ & $0.003 \pm 0.001$ \\
\hline 20-21 June $2016^{*}$ & $-0.049 \pm 0.006$ & $-0.002 \pm 0.000$ \\
\hline 7-8 July 2016* & $-0.051 \pm 0.006$ & $0.003 \pm 0.001$ \\
\hline 9-10 August 2016* & $0.009 \pm 0.002$ & $0.005 \pm 0.001$ \\
\hline 10-11 May $2017^{*}$ & $0.002 \pm 0.002$ & $0.011 \pm 0.003$ \\
\hline 21-22 June $2017^{*}$ & $0.012 \pm 0.003$ & $0.006 \pm 0.001$ \\
\hline 27-29 June 2017 & $-0.053 \pm 0.007$ & $0.002 \pm 0.001$ \\
\hline 26-27 March 2018 & $-0.058 \pm 0.006$ & $-0.004 \pm 0.001$ \\
\hline 2-3 April 2018 & $-0.056 \pm 0.011$ & $0.000 \pm 0.000$ \\
\hline 16-17 April 2018* & $-0.031 \pm 0.008$ & $0.001 \pm 0.001$ \\
\hline
\end{tabular}

moved toward the new target depth at speeds typical of many larvae (about $1 \mathrm{~cm} \mathrm{~s}^{-1}$, limited to a maximum of $10 \mathrm{~cm} \mathrm{~s}^{-1}$ ) (Young 1995). Whenever an ABLE encountered the bottom, it adjusted target depth dynamically to hover above it, avoiding dragging along it or getting lodged (Fig. ). Every 10 s, ABLEs logged temperature and depth, photosynthetically active radiation, and rate of vertical movement through the water; from these data, the depth of the surface mixed layer (thermocline depth) can be observed, and vertical currents can be derived from the difference between measured movement through water and changes in depth from the pressure sensor. We programmed ABLEs to make brief excursions to the surface at $15 \mathrm{~cm} \mathrm{~s}^{-1}$ every $4 \mathrm{~h}$ to obtain a position fix from the GPS and transmit their coordinates via Globalstar satellites to our webserver before returning to their target depth (Fig. 3). The proportion of time spent off target depth to obtain fixes ranged from $5 \%$ for $2 \mathrm{~m}$ to $7 \%$ for $16 \mathrm{~m}$, minimizing drift errors from surface currents.

We recovered ABLEs by taking a boat to the most recent position reported by satellite. If the ABLE had already surfaced for recovery, we proceeded to the latest satellite fix (updated every $20 \mathrm{~min}$ ) and homed in using pulse-encoded coordinates from a VHF radio beacon (fix updated every $10 \mathrm{~min}, 5 \mathrm{~km}$ range). Final approach relied on searching for the ultrasonic beacon using a directional hydrophone (1 km range) and the LED beacon (helpful in daylight, essential at night when it could be seen for $1.5 \mathrm{~km}$ ). If the ABLE was still submerged (had not reached its programmed recovery time), we extrapolated its probable location and searched for the ultrasonic beacon using the hydrophone. Once located, ABLEs could be re- called to the surface with an ultrasonic command. ABLEs were captured with a large dip net. Logged data were uploaded via a Bluetooth link. Software, written in R v.3.5.1 (R Core Team 2017), expedited processing, visualizing, and analyzing data.

We obtained hourly wind velocity records from the Bodega Marine Laboratory, which is located on Bodega Head. Wind velocities were rotated and decomposed to alongshore and cross-shore components (assuming a coastline angle of $320^{\circ}$ as in prior studies here; e.g. Roughan et al. 2005). We focused on the alongshore wind stress, which drives upwelling and currents. Weaker cross-shore winds do not significantly affect currents (Roughan et al. 2005), nor were they related to the observed transport of ABLEs. The trajectory of each ABLE was mapped and the mean $( \pm 1 \mathrm{SE})$ displacement was determined for each of the 3 behaviors for each deployment.

ABLE displacements were analyzed in R for all 12 deployments using generalized linear mixed models (GLMMs) fit using maximum likelihood or restricted maximum likelihood, and post hoc hypothesis testing performed with ANOVA via the statistical packages 'Ime4,' 'ImerTest,' 'stats,' and 'car'. The GLMM response variable was either the overall speed of absolute transport $\left(\mathrm{km} \mathrm{h}^{-1}\right)$ or the speed of north-south (latitudinal) transport $\left(\mathrm{km} \mathrm{h}^{-1}\right)$, which were fitted to gamma and normal distributions with natural logarithm and identity link functions, respectively. In each GLMM analysis, we fixed effects of behavior, synoptic conditions (a categorical variable indicating upwelling if mean alongshore wind stress for the deployment was negative or reversal if it was positive), and elapsed time (to account for differences in the actual length of exposure among robots and deployments), up to third-order interaction terms and a random effect of deployment date (see Table 2). Data met the assumptions of normality and equal variances.

\section{RESULTS}

Transport trajectories of ABLEs with different behaviors dramatically diverged, while those of ABLEs sharing the same behavior were very similar (Fig. 4A-F). Trajectories of DVMs differed more among deployments than for the other 2 behaviors due to differences in wind velocities at night. During northerly upwelling winds, deep ABLEs remained near the point of release, whereas near-surface ones were transported far south (Fig. 4A-C). DVM ABLEs 
traveled an intermediate distance because they were in slow bottom flow during the day while the wind was strong and reduced surface flow at night depending on how much the wind subsided (weakest in Fig. 4A). When flow reversed during wind relaxations and reversals, deep ABLEs moved little, while near-surface ABLEs moved quickly out of Bodega Bay and northward (Fig. 4D-F), like larvae displaying these behaviors evidently did in a previous study (Morgan et al. 2012). While most DVM ABLEs remained in the bay during weak nocturnal winds (Fig. 4D,F), all DVM ABLEs were flushed from the bay when strong southerly winds occurred at night (Fig. 4E).

The transport speed of ABLEs and the distance displaced were quite different for different behaviors, whereas those of ABLEs sharing the same behavior were quite similar. Net speed in all deployments was strongly affected by behaviors (Table 2, Fig. 5A). Deep ABLEs traveled slowest (mean \pm SE: $0.07 \pm$ $\left.0.01 \mathrm{~km} \mathrm{~h}^{-1}\right)$, near-surface ABLEs were fastest $(0.36 \pm$ $\left.0.04 \mathrm{~km} \mathrm{~h}^{-1}\right)$, and DVM ABLEs were intermediate $\left(0.17 \pm 0.02 \mathrm{~km} \mathrm{~h}^{-1}\right)$. When wind relaxed, speed was similar among behaviors due to strong flow reversals, except that the speed of DVM ABLEs was affected by variations in wind intensity at night (Table 2, Fig. 5A). Additionally, north-south directional rate of transport (latitudinal velocity) was affected by wind conditions (Table 2, Fig. 5B). ABLEs moved faster latitudinally (positive $=$ northward) during upwelling than reversal conditions when remaining near the surface $\left(-0.33 \pm 0.05\right.$ and $+0.25 \pm 0.07 \mathrm{~km} \mathrm{~h}^{-1}$, respectively) and when undertaking a DVM $(-0.17 \pm 0.03$ and $+0.03 \pm 0.03 \mathrm{~km} \mathrm{~h}^{-1}$ ), but not when remaining
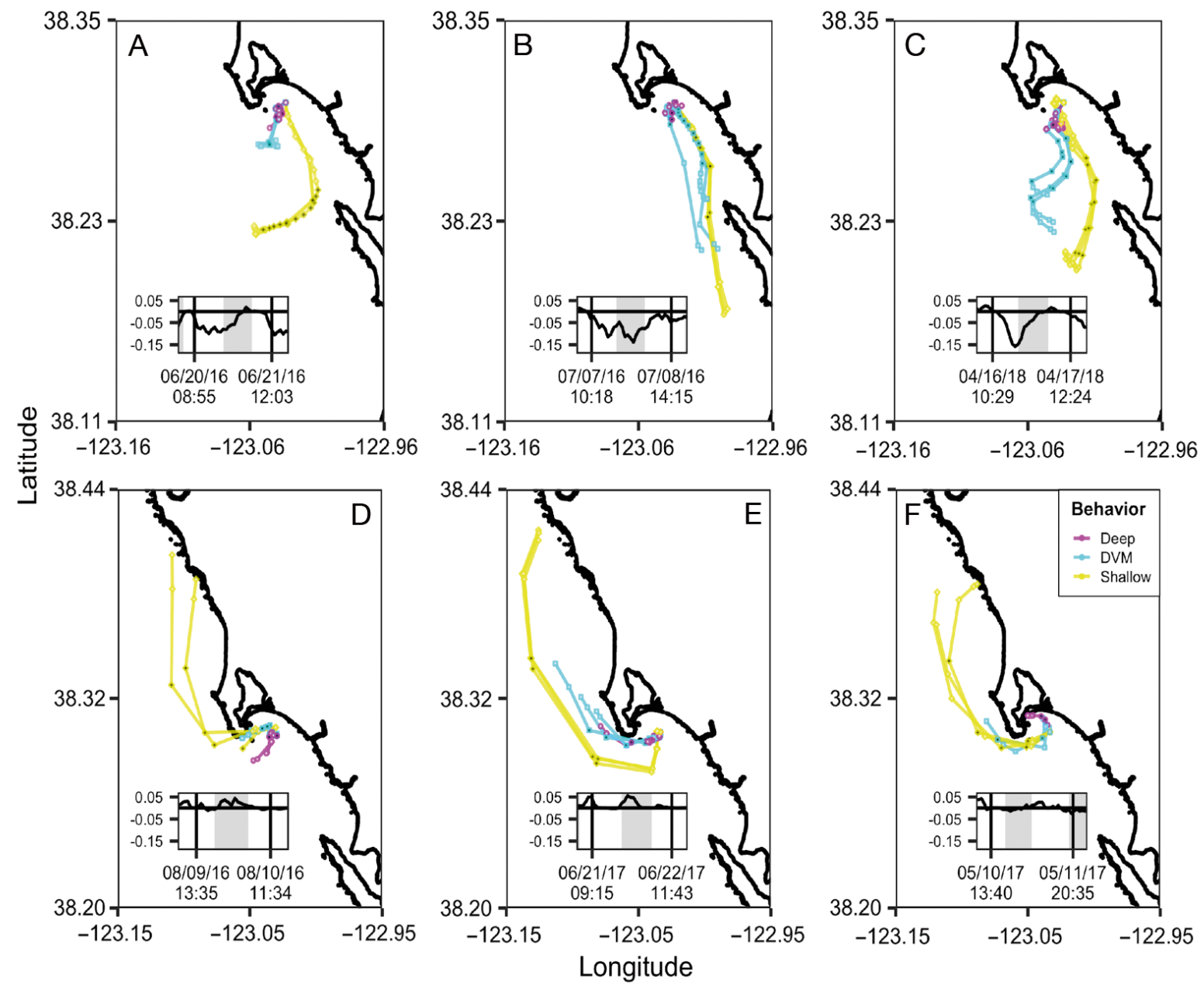

Fig. 4. Trajectories of ABLEs simulating 3 larval behaviors in upwelling and reversal conditions: 'deep' remain $16 \mathrm{~m}$ deep (or $2 \mathrm{~m}$ above bottom in shallow water); 'shallow' remain $2 \mathrm{~m}$ below surface; 'DVM' migrate from $16 \mathrm{~m}$ deep during day to $2 \mathrm{~m}$ below surface at night. Three replicates of each behavior were deployed during (A-C) upwelling winds and (D-F) weak or reversed winds. Representative results for 6 of 12 deployments are shown. Insets show wind stress: poleward (positive) and equatorward (negative). Dates given as $\mathrm{mo} / \mathrm{d} / \mathrm{yr}$ 
near bottom $\left(-0.04 \pm 0.02\right.$ and $\left.-0.04 \pm 0.02 \mathrm{~km} \mathrm{~h}^{-1}\right)$. Near-surface ABLEs always moved fastest and farthest south during upwelling and fastest and farthest north during reversal conditions (Fig. 5B). DVM ABLEs also moved south during upwelling (Fig. 5B), slowing when northerly winds subsided overnight
(Fig. 4A-C). Deep ABLEs moved little and tended to move slightly southward (Fig. 5B), regardless of wind stress (Table 2, Fig. 5C). Accordingly, total $24 \mathrm{~h}$ displacements of ABLEs from the release site were greatest for shallow ones, least for deep ones, and intermediate for those undertaking a DVM (Fig. 5D).
Table 2. General linear mixed model (GLMM) and ANOVA results testing the effect of 3 simulated larval behaviors (see Fig. 4 for details). The GLMM was fit using maximum likelihood or restricted maximum likelihood, and post hoc hypothesis testing was conducted with ANOVA. Individual fixed effects and interactions of the GLMM ( $t$-statistic) are reported as well as ANOVA of grouped effects (chi-squared test for overall velocity and $F$-test for latitudinal velocity)

\begin{tabular}{|c|c|c|}
\hline Model response/predictor & Test statistic & $\mathrm{p}$ \\
\hline \multicolumn{3}{|l|}{ Overall velocity GLMM ( $t$-statistic) } \\
\hline Deep behavior & 15.825 & $<0.001$ \\
\hline DVM behavior & 6.863 & $<0.001$ \\
\hline Shallow behavior & 10.917 & $<0.001$ \\
\hline Conditions (upwelling or reversal) & 2.627 & $<0.01$ \\
\hline Elapsed time & -3.29 & 0.001 \\
\hline DVM behavior $\times$ reversal & -3.669 & $<0.001$ \\
\hline Shallow behavior $\times$ reversal & -2.998 & 0.002 \\
\hline Shallow behavior $\times$ elapsed time & 2.059 & 0.04 \\
\hline DVM behavior $\times$ elapsed time & 1.016 & 0.31 \\
\hline Conditions $\times$ elapsed time & 0.168 & 0.87 \\
\hline DVM behavior $\times$ conditions $\times$ elapsed time & -0.74 & 0.46 \\
\hline Shallow behavior $\times$ conditions $\times$ elapsed time & -2.117 & 0.034 \\
\hline \multicolumn{3}{|l|}{ Overall velocity ANOVA ( $\chi^{2}$ statistic) } \\
\hline Behavior & 151.05 & $<0.001$ \\
\hline Conditions (upwelling or reversal) & 0.4824 & 0.49 \\
\hline Elapsed time & 15.03 & $<0.001$ \\
\hline Behavior $\times$ conditions & 16.98 & $<0.001$ \\
\hline Behavior $\times$ elapsed time & 3.4782 & 0.18 \\
\hline Conditions $\times$ elapsed time & 0.8753 & 0.35 \\
\hline Behavior $\times$ conditions $\times$ elapsed time & 4.7297 & 0.094 \\
\hline \multicolumn{3}{|l|}{ Latitudinal velocity GLMM ( $t$-statistic) } \\
\hline Deep behavior & -0.329 & 0.75 \\
\hline DVM behavior & -2.797 & $<0.01$ \\
\hline Shallow behavior & -6.605 & $<0.001$ \\
\hline Conditions (upwelling or reversal) & -0.307 & 0.76 \\
\hline Elapsed time & 1.276 & 0.21 \\
\hline DVM behavior $\times$ reversal & 2.758 & $<0.01$ \\
\hline Shallow behavior $\times$ reversal & 9.029 & $<0.001$ \\
\hline Shallow behavior $\times$ elapsed time & -1.213 & 0.23 \\
\hline DVM behavior $\times$ elapsed time & -0.362 & 0.72 \\
\hline Conditions $\times$ elapsed time & -0.594 & 0.55 \\
\hline DVM behavior $\times$ conditions $\times$ elapsed time & 0.038 & 0.97 \\
\hline Shallow behavior $\times$ conditions $\times$ elapsed time & 0.437 & 0.66 \\
\hline \multicolumn{3}{|l|}{ Latitudinal velocity ANOVA (F-statistic) } \\
\hline Behavior & 1.1505 & 0.32 \\
\hline Conditions (upwelling or reversal) & 12.2559 & $<0.01$ \\
\hline Elapsed time & 0.0476 & 0.83 \\
\hline Behavior $\times$ conditions & 42.1826 & $<0.001$ \\
\hline Behavior $\times$ elapsed time & 0.9651 & 0.39 \\
\hline Conditions $\times$ elapsed time & 0.0509 & 0.82 \\
\hline Behavior $\times$ conditions $\times$ elapsed time & 0.0964 & 0.91 \\
\hline
\end{tabular}

\section{DISCUSSION}

Our ABLE experiments demonstrated that behavior alone is sufficient to dramatically affect transport at our study site. The experiments corroborated prior numerical simulations that embedded 'behaving particles' in the sheared flow measured around Bodega Head (Roughan et al. 2005). Each vertical swimming behavior emulated by ABLE produced trajectories consistent with the model's predictions during both upwelling and relaxation conditions: shallow plankton disperse far, deep plankton move little, and DVM plankton travel an intermediate distance (Roughan et al. 2005). The experiments were also consistent with field studies of larval distributions and recruitment to adult populations. Larvae are concentrated by vertical circulation in Bodega Bay during upwelling and increase the supply of larvae to adult populations, forming a recruitment hotspot (Roughan et al. 2005, Mace \& Morgan 2006a, Morgan et al. 2011). When winds weaken or reverse, the flow reverses and these patches of larvae are flushed from the bay and travel northward, supplying larvae to populations that receive few recruits during upwelling conditions (Wing et al. 1998, Morgan et al. 2012).

How well can the movements of microscopic plankters be mimicked by mechanical surrogates that are orders of magnitude larger? The answer depends on the scale of the movements being investigated. Deployments of small robots (1 1 displacement) recently provided the first empirical support for the hypothesis that plankton maintaining depth accumulate in patches over the troughs (flow convergences) of internal waves (Jaffe et al. 2017). Sixteen robots were programmed to maintain $10 \mathrm{~m}$ depth and were tracked by an array of acoustic transmitting floats for $5 \mathrm{~h}$ as internal waves passed through. Like ABLEs, those robots 

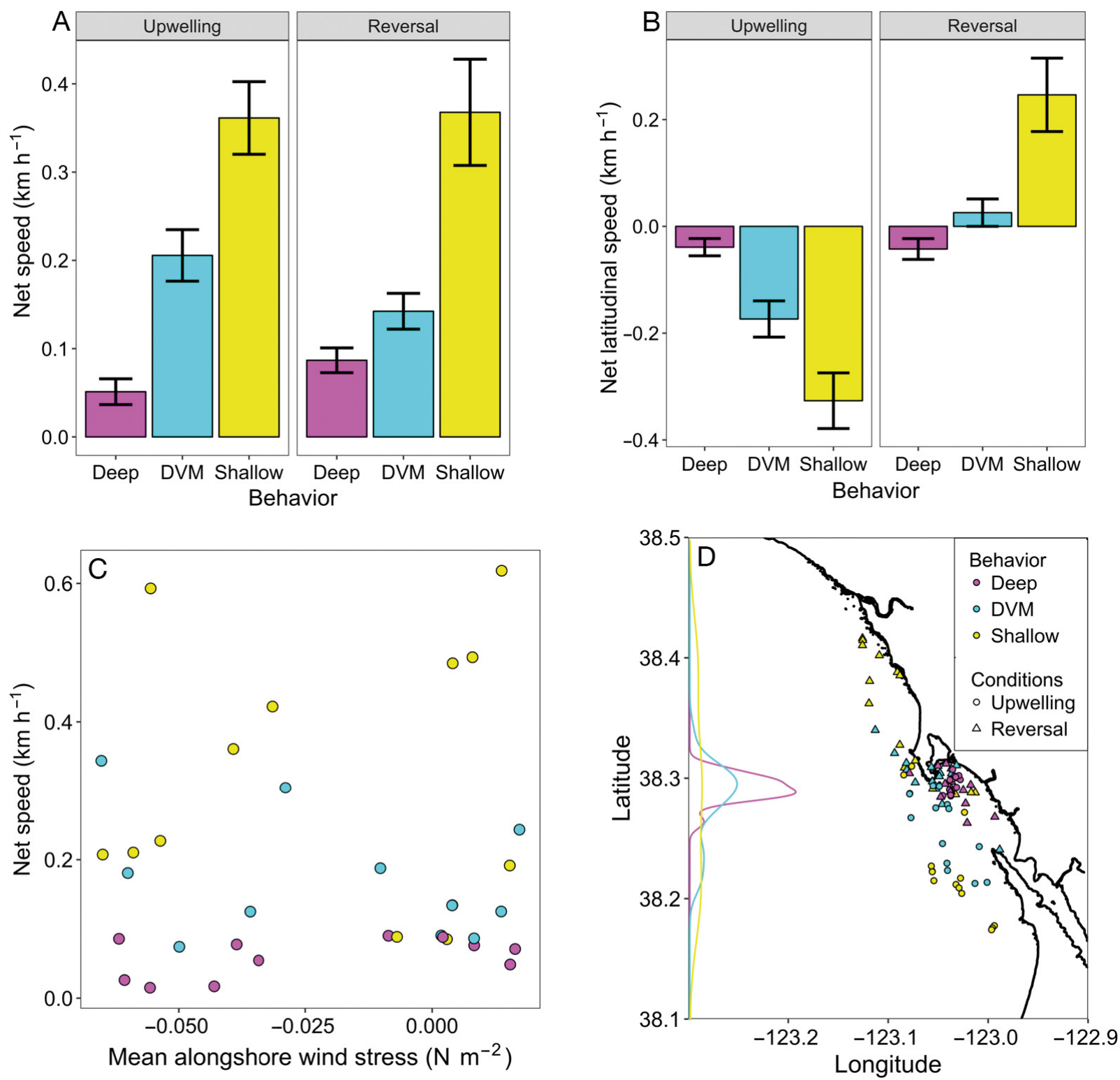

Fig. 5. Transport rates and displacement of ABLEs simulating 3 larval behaviors relative to wind conditions. (A) Net $( \pm 1$ SE) speed traveled, (B) Net ( \pm 1 SE) latitudinal speed, (C) Net speed relative to wind stress, and (D) final locations for all 12 deployments illustrating the diversity of outcomes (dispersion) and smoothed frequency distribution of final latitudinal positions (colored lines) for each behavior and wind scenario

capture the essential effects of transport in vertically sheared flow. They do not capture how small-scale turbulence drives separation (dispersion) of plankters at scales smaller than the body of the robot. While small-scale turbulence may be important in high shear between currents flowing in opposite directions, transport is dominated by advection within surface and lower layers (high Peclet number; Largier 2003).

ABLEs thus capture dispersion at scales greater than their size (Nyquist wavenumber of about $0.5 \mathrm{~m}$ given a drag length scale of about $0.25 \mathrm{~m}$ ). If spread, $\sigma$, is the maximum distance between any 2 ABLEs in a behavioral group, then dispersion, $D$, is given by the relationship $\sigma(t)=\sqrt{2 D t}$ (Fischer et al. 1979). Spread varied from about $15 \mathrm{~m} \mathrm{~h}^{-1}$ for deep ABLEs during upwelling to $90 \mathrm{~m} \mathrm{~h}^{-1}$ for shallow ABLEs during relaxation so that dispersion estimates were on the order of $10^{2}$ to $10^{4} \mathrm{~m}^{2} \mathrm{~h}^{-1}$. Dispersion due to motions at scales smaller than $0.25 \mathrm{~m}$ is typically on the order of only $10^{-3}$ to $10^{-1} \mathrm{~m}^{2} \mathrm{~h}^{-1}$ (Rothschild \& Osborn 1988), much smaller than observed, showing that 
small-scale turbulence is not a significant factor in transport of ABLEs. ABLEs may also be influenced by vertical excursions caused by turbulence, but only by motions at scales greater than their size. Using the same scaling argument applied above to compare the effect of small-scale turbulent motion on the vertical position of microscopic plankton with that of vertical motions on scales sampled by ABLEs again revealed that the effects of small-scale turbulence are negligible compared to those of larger-scale water motions.

The ability of plankton to control transport fundamentally affects our understanding of the ecology and evolution of life in the sea. Species remaining deep move little during both upwelling and relaxation events (Peterson 1998, Morgan et al. 2009c, 2018, Morgan \& Fisher 2010, Drake et al. 2013), resulting in retention near natal populations and increasing the potential for local adaptation, high recruitment, and dense, space-limited adult populations (Strathmann et al. 2002, Morgan 2001, 2014, 2020, Sanford \& Kelly 2011). In contrast, species that primarily occur near-surface disperse much farther away (Peterson 1998, Morgan et al. 2009c, 2018, Morgan \& Fisher 2010, Morgan 2014, Drake et al. 2013), potentially increasing population connectivity and gene flow (Strathmann et al. 2002, Morgan 2014, 2020, Burgess et al. 2014, 2016). Species undertaking a DVM (Peterson 1998, Morgan \& Fisher 2010) are retained when winds subside at night and disperse when they persist, yielding diverse outcomes when aggregated over the reproductive season and across regions with varying diel wind cycles (Fig. 4D). Many species that change behavior ontogenetically facilitate seaward dispersal early in development by occurring near the surface and limit or reverse it later in planktonic life by occurring near the bottom (Peterson 1998, Morgan et al. 2009c, 2018, Morgan \& Fisher 2010), thereby avoiding predation nearshore where fishes are abundant (Morgan 1990, Morgan \& Anastasia 2008).

Field studies in estuaries and across the continental shelf throughout the world have shown that vertical and horizontal distributions of plankters are correlated, regardless of whether species permanently reside in the plankton or develop there temporarily as larvae (Peterson 1998, Epifanio \& Garvine 2001, Shanks \& Brink 2005, Kunze et al. 2013, Morgan 2020). In upwelling regimes, larvae of most nearshore invertebrates and copepods remain deep or perform DVMs throughout development, and all larval stages tend to occur within a few $\mathrm{km}$ of shore, suggesting that the surviving larvae avoided being swept offshore (Peterson 1998, Fisher et al. 2014,
Morgan 2014, Bonicelli et al. 2016, Hameed et al. 2018). Larvae of other nearshore species occur various distances from shore early and occur nearshore later in development, and these cross-shelf migrations are evidently mediated by species-specific differences in ontogenetic vertical positioning in sheared currents (Peterson 1998, Fisher et al. 2014, Morgan 2014, Bonicelli et al. 2016, Hameed et al. 2018). ABLE trajectories demonstrated that behavior has a primary and causal role in producing the observed distributions: by changing their vertical position, plankton can exert considerable control over their transport in nature. On rocky shores in upwelling regimes, such behaviors can modulate larval supply and recruitment dynamics (Drake et a. 2013, Morgan 2014, Shanks \& Morgan 2018), so the probability of larvae being swept offshore and lost at sea can no longer be assumed to be simply a function of regional differences in the strength and persistence of upwelling, as has been argued for over $30 \mathrm{yr}$ (Roughgarden et al. 1988, Menge \& Menge 2013). Rather, larval supply fundamentally depends on the interaction between interspecific differences in vertical swimming behaviors of larvae and spatial and temporal variation in current flow. Larval mortality and other variables also affect the distribution, supply, and recruitment of larvae, but ABLE trajectories clearly demonstrate that behavior alone has profound effects on larval dispersal in the sea.

Acknowledgements. H. Killeen, S. McAfee and D. Dann assisted in the field. We thank the captain and crew of the R/V 'Mussel Point'. Comments by R. Grosberg, S. Bashevkin, and $\mathrm{H}$. Killeen improved the manuscript. S. Small assisted with drafting Fig. 2. This is a contribution of the Bodega Marine Laboratory. This research was supported by the National Science Foundation (OCE-1334448) and California Sea Grant (NA18OAR4170073).

\section{LITERATURE CITED}

Arvedlund M, Kavanagh K (2009) The senses and environmental cues used by marine larvae of fish and decapod crustaceans to find tropical coastal ecosystems. In: Kerken IN (ed) Ecological connectivity among tropical coastal ecosystems. Springer Science + Business Media, Frederiksberg, p 135-184

Bonicelli J, Tyburczy J, Tapia FJ, Finke GR and others (2016) Diel vertical migration and cross-shore distribution of barnacle and bivalve larvae in the central Chile inner-shelf. J Exp Mar Biol Ecol 485:35-46

Bousfield EL (1955) Ecological control of the occurrence of barnacles in the Miramichi estuary. Bull Natl Mus Can 137:1-69

Broitman BR, Blanchette CA, Menge BA, Lubchenco J and others (2008) Spatial and temporal patterns of invertebrate recruitment along the west coast of the United States. Ecol Monogr 78:403-421 
Burgess SC, Nickols KJ, Griesemer CD, Barnett LAK and others (2014) Beyond larval connectivity: how empirical methods can quantify population persistence to improve marine protected area design. Ecol Appl 24:257-270

Burgess SC, Baskett ML, Grosberg RK, Morgan SG, Strathmann RR (2016) When is dispersal for dispersal? Unifying marine and terrestrial perspectives. Biol Rev Camb Philos Soc 91:867-882

* Caley MJ, Carr MH, Hixon MA, Hughes TP, Jones GP, Menge BA (1996) Recruitment and the local dynamics of open marine populations. Annu Rev Ecol Syst 27: $477-500$

Cowen RK, Sponaugle S (2009) Larval dispersal and marine population connectivity. Annu Rev Mar Sci 1:443-446

Cronin TW, Forward RB Jr (1986) Vertical migration cycles of crab larvae and their role in larval dispersal. Bull Mar Sci 39:192-201

DeWolf P (1973) Ecological observations on the mechanisms of dispersal of barnacle larvae during planktonic life and settling. Neth J Sea Res 6:1-129

Dorman CE, Dever EP, Largier JL (2006) Buoy measured wind, wind stress and curl of the wind stress over the shelf off Bodega Bay, California. Deep Sea Res II 53: 2850-2864

Drake PT, Edwards CA, Morgan SG, Dever EP (2013) Influence of behavior on larval dispersal and population connectivity in a realistic simulation of the California Current System. J Mar Res 71:317-350

Epifanio CE, Cohen JH (2016) Behavioral adaptations in larvae of brachyuran crabs: a review. J Exp Mar Biol Ecol 482:85-105

Epifanio CE, Garvine RW (2001) Larval transport on the Atlantic continental shelf of North America: a review. Estuar Coast Shelf Sci 52:51-77

Fischer HB, List EJ, Koh RCY, Imberger J, Brooks NH (1979) Mixing in inland and coastal waters. Academic Press, New York, NY

Fisher JL, Peterson WT, Morgan SG (2014) Does latitudinal variation in the intensity and persistence of upwelling regulate larval advection and supply? Mar Ecol Prog Ser 503:123-137

*Hameed SO, Elliott ML, Morgan SG, Jahncke J (2018) Interannual variation and spatial distribution of decapod larvae in a region of persistent coastal upwelling. Mar Ecol Prog Ser 587:55-71

Hickey B (1998) Coastal oceanography of Western North America from the tip of Baja California to Vancouver Island. In: Robinson A, Brink KH (eds) The sea: ideas and observations on progress in the study of the seas. John Wiley \& Sons, New York, NY, p 10339-10368

Hjort J (1914) Fluctuations in the great fisheries of Northern Europe viewed in the light of biological research. Rapp P-V Reun Cons Int Explor Mer 20:1-228 p

Jaffe JS, Franks PJS, Roberts PLD, Mirza D, Schurgers C, Kastner R, Boch A (2017) A swarm of autonomous miniature underwater robot drifters for exploring submesoscale ocean dynamics. Nat Commun 8:14189

Jones GP, Almany GR, Russ GR, Sale PF, Steneck RS, Oppen MJH, Willis BL (2009) Larval retention and connectivity among populations of corals and reef fishes: history, advances and challenges. Coral Reefs 28:307-325

Kingsford MJ, Leis J, Shanks A, Lindeman K, Morgan S, Pineda J (2002) Sensory environments, larval abilities and local self-recruitment. Bull Mar Sci 70:309-340

Kunze HB, Morgan SG, Lwiza KMM (2013) A field test of the behavioral regulation of larval transport. Mar Ecol Prog Ser 487:71-87

Largier JL (2003) Considerations in estimating larval dispersal distances from oceanographic data. Ecol Appl 13: S71-S89

Kargier JL, Magnell BA, Winant CD (1993) Subtidal circulation over the Northern California Shelf. J Geophys Res 98:18147-18179

KLeis JM, Siebeck U, Dixson DL (2011) How Nemo finds home: the neuroecology of dispersal and of population connectivity in larvae of marine fishes. Integr Comp Biol 51:826-843

Mace AJ, Morgan SG (2006a) Larval accumulation in the lee of a small headland: implications the design of marine reserves. Mar Ecol Prog Ser 318:19-29

Mace AJ, Morgan SG (2006b) Biological and physical coupling in the lee of a small headland: contrasting larval transport mechanisms in an upwelling region. Mar Ecol Prog Ser 324:185-196

McCleave JD, Wippelhauser GS (1987) Behavioral aspects of selective tidal stream transport in juvenile American eel (Anguilla rostrata). Am Fish Soc Symp 1:138-150

* Menge BA, Menge DNL (2013) Dynamics of coastal metaecosystems: the intermittent upwelling hypothesis and a test in rocky intertidal regions. Ecol Monogr 83:283-310

*Menge BA, Lubchenco J, Bracken MES, Chan F and others (2003) Coastal oceanography sets the pace of rocky intertidal community dynamics. Proc Natl Acad Sci USA 100:12229-12234

* Morgan SG (1990) Impact of planktivorous fishes on the dispersal, hatching and morphology of estuarine crab larvae. Ecology 71:1639-1652

Morgan SG (1995) The timing of larval release. In: McEdward L (ed) Ecology of marine invertebrate larvae. CRC Press, Boca Raton, FL, p 157-192

Morgan SG (2001) The larval ecology of marine communities. In: Bertness M, Gaines SD, Hay M (eds) Marine community ecology. Sinauer Associates, Sunderland, MA, p 158-181

*Morgan SG (2014) Behaviorally mediated larval transport in upwelling systems. Adv Oceanogr 2014:364214

Morgan SG (2020) Dispersal. In: Anger K, Harzsch S, Thiel $\mathrm{M}$ (eds) The natural history of the Crustacea, Vol 8. Academic Press, New York, NY, p 383-407

* Morgan SG, Anastasia JR (2008) Larval behavior conserves transport while increasing the risk of predation across the ranges of marine species. Proc Natl Acad Sci USA 105:222-227

Morgan SG, Fisher JL (2010) Larval behavior regulates nearshore retention and offshore migration in an upwelling shadow and along the open coast. Mar Ecol Prog Ser 404:109-126

* Morgan SG, Fisher JL, Mace JL (2009a) Larval recruitment in a region of strong, persistent upwelling and recruitment limitation. Mar Ecol Prog Ser 394:79-99

*Morgan SG, Fisher JL, Mace JL, Akins L, Slaughter AM, Bollens SM (2009b) Cross-shelf distributions and recruitment of crab postlarvae in a region of strong upwelling. Mar Ecol Prog Ser 380:173-185

* Morgan SG, Fisher JL, Miller SH, McAfee ST, Largier JL (2009c) Nearshore larval retention in a region of strong upwelling and recruitment limitation. Ecology 90: 3489-3502

Morgan SG, Fisher JL, Largier JL (2011) Laval retention, entrainment and accumulation in the lee of a small head- 
land: recruitment hotspots along windy coasts. Limnol Oceanogr 56:161-178

Morgan SG, Fisher JL, McAfee ST, Largier JL, Halle CM (2012) Limited recruitment during relaxation events: larval advection and behavior in an upwelling system. Limnol Oceanogr 57:457-470

Morgan SG, Miller SH, Robart M, Largier JL (2018) Nearshore larval retention and cross-shelf migration of benthic crustaceans at an upwelling center. Front Mar Sci $5: 161$

Naylor E (2006) Orientation and navigation in coastal and estuarine zooplankton. Mar Freshwat Behav Physiol 39:13-24

Nickols KJ, Miller SH, Gaylord B, Morgan SG, Largier JL (2013) Spatial differences in larval supply within the coastal boundary layer impact availability to shoreline habitats. Mar Ecol Prog Ser 494:191-203

Peterson WT (1998) Life cycle strategies of copepods in coastal upwelling zones. J Mar Res 15:313-326

Queiroga H, Blanton J (2005) Interactions between behaviour and physical forcing in the control of horizontal transport of decapod crustacean larvae. Adv Mar Biol 47:107-214

R Core Team (2017) R: a language and environment for statistical computing. R Foundation for Statistical Computing, Vienna

Rothschild BJ, Osborn TR (1988) Small-scale turbulence and plankton contact rates. J Plankton Res 10:465-474

Roughan M, Mace AJ, Largier JL, Morgan SG, Fisher JL, Carter ML (2005) Density driven headland retention in a strong upwelling system: implications for larval transport. J Geophys Res 110:C10027

Roughgarden J, Gaines SD, Possingham HP (1988) Recruitment dynamics in complex life cycles. Science 241: 1460-1466

Sanford E, Kelly MW (2011) Local adaptation in marine invertebrates. Annu Rev Mar Sci 3:509-535

Scheltema RS (1975) Relationship of larval dispersal, geneflow and natural selection to geographic variation of benthic invertebrates in estuaries and along shorelines.

Editorial responsibility: Alejandro Gallego,

Aberdeen, UK

Reviewed by: 3 anonymous referees
In: Crosonin LE (ed) Estuarine research. Academic Press, New York, NY, p 372-391

Shanks AL, Brink L (2005) Upwelling, downwelling, and cross-shelf transport of bivalve larvae: test of a hypothesis. Mar Ecol Prog Ser 302:1-12

Shanks AL, Morgan SG (2018) Testing the intermittent upwelling hypothesis: upwelling, downwelling, and subsidies to the intertidal zone. Ecol Monogr 88:22-35

Strathmann RR, Hughes TP, Kuris AM, Lindeman KC, Morgan SG, Pandolfi JM, Warner RR (2002) Evolution of selfrecruitment and its consequences for marine populations. Bull Mar Sci 70:377-396

Swearer S, Thorrold S, Shima J, Hellberg M and others (2002) Evidence for self-recruitment in benthic marine populations. Bull Mar Sci 70:251-272

* Thorson G (1950) Reproductive and larval ecology of marine bottom invertebrates. Biol Rev Camb Philos Soc 25:1-45

*Vincent JFV, Bogatyreva OA, Bogatyrev NR, Bowyer A, Pahl AK (2006) Biomimetics: its practice and theory. J R Soc Interface 3:471-482

White JW, Morgan SG, Fisher JL (2014) Larval mortality rates are lower than widely expected. Ecology 95: 3344-3353

Wing SR, Botsford L, Ralston SV, Largier JL (1998) Meroplanktonic distribution and circulation in a coastal retention zone of the northern California upwelling system. Limnol Oceanogr 43:1710-1721

*Woodson CB, McManus MA, Tyburczy JA, Barth JA and others (2012) Coastal fronts set recruitment and connectivity patterns across multiple taxa. Limnol Oceanogr 57:582-596

Young CM (1986) Direct observations of field swimming behavior in larvae of the colonial ascidian Ecteinascidia turbinata. Bull Mar Sci 96:279-289

Y Young CM (1990) Larval ecology of marine invertebrates: a sesquicentennial history. Ophelia 32:1-48

Young CM (1995) Behavior and locomotion during the dispersal phase of larva life. In: McEdward L (ed) Ecology of marine invertebrate larvae. CRC Press, Boca Raton, FL, p 249-277

Submitted: May 23, 2020

Accepted: January 8, 2021

Proofs received from author(s): March 15, 2021 